\section{Limitations on the use of platelet concentrate as a graft material and scaffold for bone regeneration.}

\author{
Pedro C. Aravena. ${ }^{1,2,3}$
}

Bone is a dynamic an important component of our body that is constantly being appositioned and reabsorbed. However, aging and chronic diseases modify its biological homeostasis producing large bone defects, hypocalcification and even fractures. Actually, tissue engineering applies knowledge of bioengineering, cell transplantation and the manufacture of biological substitutes that can restore and maintain normal bone function (Cypher \& Grossman, 1996). For this purpose, it is necessary to have a graft material that meets the biological properties of autogenous bone: to have an osteogenic, osteoconductive and osteoinductive potential, with a rapid incorporation and consolidation (Cypher \& Grossman, 1996). Currently in the market there are deproteinized bone substitutes of human / animal origin or synthetic biomaterials. Mineral substitutes come in common from a bone that can be freeze dried or demineralized and deproteinized, so its mineral base is generally based on tricalcium phosphate particles (TCP) and Hydroxyapatite crystals. On the other hand, the scaffold of human / animal origin is marketed as Demineralized Bone Matrix (DBM) and consists of decalcified bone (residual calcium $<5 \%$ ) with a collagen matrix and the presence of bone-inducing growth factors capable of stimulating the activation and migration of osteogenic stem cells and progenitor cells, and induce revascularization (Campana et al., 2014).

While mineral substitutes and DBM have demonstrated their effectiveness in bone formation, new findings have shown that the type and quality of bone is not biologically similar to the subject's native bone, with a scar-like acellular bone without lacunas typically seen between osteoclasts in resorbing bone surfaces (Mordenfeld et al., 2010). It has also been demonstrated that the effect of new bone formation is limited by the waiting time for the maxillae to incorporate, absorb and regenerate the graft material. The presence of intact graft particles up to fourteen years (lezzi et al., 2007), with the constant presence of large giant cells around the particulate and a constant size of the original particles (40-400 $\mu \mathrm{m}$ ) have been observed and a lower percentage of new laminar bone formation (between 14\% and $40 \%$ ) (Mordenfeld et al., 2010)

According to these antecedents, the use of the patient's own blood as scaffold would allow to form the required bone. This is possible to achieve through the controlled centrifugation of blood by obtaining platelet concentrates in a fibrin network and releasing growth factors and bioactive proteins to initiate and accelerate tissue repair and regeneration (Altmeppen
INT J MED SURG SCI
Affiliation: ${ }^{1}$ Institute of Anatomy, Histology and Pathology. Faculty of Medicine. Universidad Austral de Chile. ${ }^{2}$ School of Dentistry. Faculty of Medicine. Universidad Austral de Chile. ${ }^{3}$ Department of Dental Implant Surgery, São Leopoldo Mandic School and Dental Institute, Campinas, SP, Brazil.

Corresponding author: Dr. Pedro C. Aravena. Escuela de Odontología, Facultad de Medicina, Universidad Austral de Chile. Campus Isla Teja s/n. Valdivia, Chile. Phone: +56999980727 .

E-mail: paravenat@gmail.com.

Conflict of interests: None.

Acknowledgements: None.

doi: $10.32457 / \mathrm{ijmss} .2018 .032$. 
et al., 2004). Compared with the most widely used scaffolds, platelet concentrates combine some important advantages such as high efficiency and cellular distribution (Swartz et al., 2005), adhesion capacity (Rosso et al., 2005), being cost-effective and safe for the patient, decreasing the potential risk of immune reaction or infection by a foreign body.

The first uses in the oral and maxillofacial territory were described in 1997 and defined as platelet-rich plasma (PRP) (Marx et al., 1998) and then in 2001 the second generation called platelet-rich fibrin (PRF) defined with biological characteristics much higher than its predecessor, mainly due to its metabolic capacity on osteoblasts in the production of alkaline phosphatase and osteocalcin (Wang et al., 2017).

There are several studies in animal model that demonstrate the effectiveness of the use of platelet concentrate in the formation of biologically stable bone compared to the use of inorganic or collagen matrices (Skwarcz et al., 2019), and even favor the repair of exposed fractures (Dülgeroglu \& Metineren, 2017). However, in models of maxillary sinus lift elevation in sheep showed that the use of PRF had lower bone density compared to the use of autogenous bone-allograft mixture, and even presenting remains of the platelet concentrate after 9 months of surgery (Ocak et al., 2017). Therefore, the use of platelet concentrate (PRP, PRF or its derivatives) should be analyzed with caution, since there are reports that analyze the risk of bias presented in the reports highlighting important limitations in terms of low quality and high heterogeneity, hindering the understanding of the achievement of the observed results to be used in a general way in the daily clinic.

\section{REFERENCES}

Altmeppen J, Hansen E, Bonnländer GL, Horch RE, Jeschke MG. Composition and characteristics of an autologous thrombocyte gel. J. Surg. Res. 2004;117(2): 202-7.

Campana V, Milano G, Pagano E, Barba M, Cicione C, Salonna G, Lattanzi W, Logroscino G. Bone substitutes in orthopaedic surgery: from basic science to clinical practice. J Mater Sci Mater Med. 2014;25(10):2445-61.

Cypher TJ, Grossman JP. Biological principles of bone graft healing. J Foot Ankle Surg. 1996;35(5):413-7.

Dülgeroglu TC, Metineren H. Evaluation of the Effect of
Platelet-Rich Fibrin on Long Bone Healing: An Experimental Rat Model. Orthopedics. 2017;40(3):e479-e484.

Iezzi G, Degidi M, Scarano A, Petrone G, Piattelli A. Anorganic bone matrix retrieved 14 years after a sinus augmentation procedure: a histologic and histomorphometric evaluation. J Periodontol. 2007;78(10):2057-61.

Marx RE, Carlson RM, Eichstaedt RM, Schimmele SR, Strauss JE. Georgeff KR. Platelet-rich plasma: growth factor enhancement for bone grafts. Oral Surg Oral Med Oral Pathol Oral Radiol Endod. 1998;85(6): 638-646.

Mordenfeld A, Hallman M, Johansson CB, Albrektsson T. Histological and histomorphometrical analyses of biopsies harvested 11 years after maxillary sinus floor augmentation with deproteinized bovine and autogenous bone. Clin Oral Implants Res. 2010;21(9):961-70.

Ocak H, Kutuk N, Demetoglu U, Balcıoglu E, Ozdamar S, Alkan A. Comparison of Bovine Bone-Autogenic Bone Mixture Versus Platelet-Rich Fibrin for Maxillary Sinus Grafting: Histologic and Histomorphologic Study. J Oral Implantol. 2017;43(3):194-201.

Rosso F, Marino G, Giordano A, Barbarisi M, Parmeggiani D, Barbarisi A. Smart materials as scaffolds for tissue engineering. J Cell Physiol. 2005;203(3):465-70.

Skwarcz S, Bryzek I, Gregosiewicz A, Warda E, Gawęda K, Tarczyńska M, Węgłowski R, Skwarcz J, Nadulski R, Starek A, Sanford J. Autologous activated platelet-rich plasma (PRP) in bone tissue healing - does it work? Assessment of PRP effect on bone defect healing in animal models. Pol J Vet Sci. 2019;22(1):109-115.

Swartz DD, Russell JA, Andreadis ST. Engineering of fibrinbased functional and implantable small-diameter blood vessels. Am J Physiol Heart Circ Physiol. 2005; 288(3):H1 451-60.

Wang X, Zhang Y, Choukroun J, Ghanaati S, Miron RJ. Effects of an injectable platelet-rich fibrin on osteoblast behavior and bone tissue formation in comparison to platelet-rich plasma. Platelets. 2018;29(1):48-55.

Aravena PC. Limitations on the use of platelet concentrate as a graft material and scaffold for bone regeneration. Int J Med Surg Sci. 2018; 5(4): 128-129. doi: 10.32457/ijmss.2018.032. 